\title{
LRMSC Grade 1, Skin
}

National Cancer Institute

\section{Source}

National Cancer Institute. LRMSC Grade 1, Skin. NCI Thesaurus. Code C121170.

Slight atrophy; pigmentation change; some hair loss. 